\title{
Peripheral concentrations of inhibin A, ovarian steroids, and gonadotropins associated with follicular development throughout the estrous cycle of the sow
}

\author{
Michiko Noguchi ${ }^{1,2}$, Koji Yoshioka ${ }^{2}$, Seigo Itoh ${ }^{1}$, Chie Suzuki ${ }^{2}$, Sachiko Arai ${ }^{1}$, Yasunori Wada ${ }^{1}$, \\ Yoshihisa Hasegawa ${ }^{3}$ and Hiroyuki Kaneko ${ }^{4}$ \\ ${ }^{1}$ Laboratory of Veterinary Internal Medicine, Azabu University, Sagamihara, Kanagawa 229-8501, Japan, ${ }^{2}$ Research \\ Team for Production Diseases, National Institute of Animal Health, Tsukuba, Ibaraki 305-0856, Japan, ${ }^{3}$ Laboratory \\ of Experimental Animal Science, Kitasato University, Towada, Aomori 034-8628, Japan and ${ }^{4}$ Reproductive Biology \\ Research Unit, National Institute of Agrobiological Sciences, 2-1-2 Kannondai, Tsukuba, Ibaraki 305-8602, Japan
}

Correspondence should be addressed to H Kaneko; Email: kaneko@affrc.go.jp

\begin{abstract}
We investigated changes in peripheral concentrations of inhibin A, total inhibin, steroids, and gonadotropins throughout the intact estrous cycle of the sow in relation to ovarian changes determined by daily transrectal ultrasonography. All visible follicles of $3 \mathrm{~mm}$ or more in diameter were classified as small $(\geq 3$ and $<6 \mathrm{~mm}$ ) or large $(\geq 6 \mathrm{~mm}$ ). Follicular recruitment was identified in two periods of the cycle: one from the late luteal to the follicular phase, characterized by an increase in the number of small follicles followed by the appearance of large follicles; and another during the early luteal phase, consisting only of increased numbers of small follicles. Plasma concentrations of inhibin $A$ increased $(P<0.05)$, coinciding with the two periods of follicle emergence. Estradiol $\left(E_{2}\right)$ levels increased $(P<0.05)$ during the follicular phase, but not during the early luteal phase. An inverse relationship $(P<0.01)$ between the patterns of inhibin and FSH concentrations was noted around the two periods of follicle emergence, but there was no relationship $(P \geq 0.1)$ between the patterns of plasma $E_{2}$ and FSH during the early luteal phase. In conclusion, measurement of plasma inhibin $A$ levels combined with ultrasonographic examination of the ovaries revealed two periods of synchronous follicular growth during the sow's estrous cycle. The results strongly suggest that inhibin A functions as a negative feedback regulator of FSH secretion throughout the estrous cycle, whereas $E_{2}$ appears to influence FSH secretion only during the follicular phase.

Reproduction (2010) 139 153-161
\end{abstract}

\section{Introduction}

Combined analyses of hormonal profiles and ovarian cycles in the sow's estrous cycle can provide us with basic knowledge with which we can manipulate follicular growth to improve porcine reproductive efficiency. Earlier studies based on morphological analyses of follicular populations have suggested that continuous growth and regression of follicles smaller than $6 \mathrm{~mm}$ in diameter occur during the porcine estrous cycle, except in the follicular phase, when several 'co-dominant' follicles are selected and grow synchronously (Clark et al. 1975, Kelly et al. 1988a). The results of an ultrasound scanning study of follicular growth in the pig ovary support this concept (Ryan et al. 1994). However, classification of each follicle by the incidence of granulosa cell apoptosis and by follicular estradiol $\left(E_{2}\right)$ concentration suggests the occurrence of synchronous growth and regression of small follicles during the early luteal phase (Guthrie et al. 1995a, 1995b).
Moreover, circulating total inhibin levels show small but clear peaks during the early luteal phase of the sow's estrous cycle (Hasegawa et al. 1988), suggesting the existence of coordinated recruitment and regression of follicles. Characterization of follicular growth in the porcine estrous cycle therefore remains open to dispute.

Endocrine events in the peripheral circulation have been studied during the porcine estrous cycle. These studies include analyses of changes in the concentrations of gonadotropins (van de Wiel et al. 1981, Hasegawa et al. 1988, Kelly et al. 1988b, Guthrie \& Bolt 1990, Knox et al. 2003), ovarian steroids (van de Wiel et al. 1981, Hasegawa et al. 1988, Knox et al. 2003), and total inhibin (Hasegawa et al. 1988, Mukai et al. 1989, Trout et al. 1992, Knox et al. 2003). However, the temporal relationships between follicular dynamics and hormonal profiles throughout the estrous cycle have not yet been clarified in the pig, although such combined analyses have given us new knowledge about the control of follicular growth in sheep (Ginther et al. 1995), 
cattle (Adams et al. 1992, Bleach et al. 2001, Kaneko et al. 2002a, Todoroki et al. 2004), and goats (Medan et al. 2003). Moreover, interpretation of the inhibin profiles obtained by the inhibin immunoassays used in the above studies (Hasegawa et al. 1988, Mukai et al. 1989, Trout et al. 1992, Knox et al. 2003) involves uncertainty. The ovary synthesizes inhibin dimers (inhibin $A$, a dimer of $\alpha$ and $\beta_{\mathrm{A}}$ subunits; and inhibin $\mathrm{B}$, a dimer of $\alpha$ and $\beta_{\mathrm{B}}$ ) that have FSH-suppressing activity (Ling et al. 1985, Miyamoto et al. 1985, Rivier et al. 1985, Robertson et al. 1985, Fukuda et al. 1986); it also produces substantial amounts of free $\alpha$ subunits of inhibin that have no FSH-suppressing activity (Knight et al. 1989, Robertson et al. 1989, Sugino et al. 1989). However, because the assays used in previous studies were based on antisera directed against the $\alpha$ subunits of inhibin (Hasegawa et al. 1988, Mukai et al. 1989, Trout et al. 1992, Knox et al. 2003), they did not discriminate the dimeric inhibins from the free $\alpha$ subunits. To overcome this major limitation in inhibin assays, we have developed a sandwich-type time-resolved immunofluorometric assay (Tr-IFMA) for dimeric inhibins, which uses a combination of $\alpha$ and $\beta_{\mathrm{A}}$ or $\beta_{\mathrm{B}}$ antibodies (Hasegawa et al. 1997, Kaneko et al. 2002a, 2003). Tr-IFMA has proven to be applicable to the measurement of inhibin A or/and B in humans (Hasegawa et al. 1997), rats (Hasegawa et al. 1997), cattle (Kaneko et al. 2002a, 2003, 2006, Todoroki et al. 2004), and boars (Ohnuma et al. 2007). Other groups have quantified dimeric inhibins in the circulation of humans (Groome et al. 1994, 1996), rats (Fahy et al. 1995, Woodruff et al. 1996), cattle (Bleach et al. 2001), and sheep (Knight et al. 1998) with sandwich-type ELISAs. Our present study was designed to 1) examine whether Tr-IFMAs for dimeric inhibins are applicable to female pigs and, if so, 2) clarify the changes in the levels of dimeric inhibins in the circulation throughout the porcine estrous cycle in relation to follicular growth and the profiles of $\mathrm{FSH}$ and $\mathrm{E}_{2}$.

\section{Results}

\section{Validation of time-resolved fluoroimmunoassay and Tr-IFMA of porcine inhibin}

After fractionation of porcine follicular fluid (pFF) by a combination of immunoaffinity chromatography and SDS-PAGE, fluoroimmunoassay (FIA) for total inhibin detected high immunoreactivity, with peak molecular mass values of 30, 50, 72, and $108 \mathrm{kDa}$ (Fig. 1a). Inhibin A IFMA also recognized, but more specifically, four high immunoreactivity peaks of the same molecular weights (Fig. 1b). Inhibin B IFMA likewise detected peaks corresponding to the same molecular weight, but each peak value was approximately one-tenth of that determined by inhibin A IFMA (Fig. 1C).
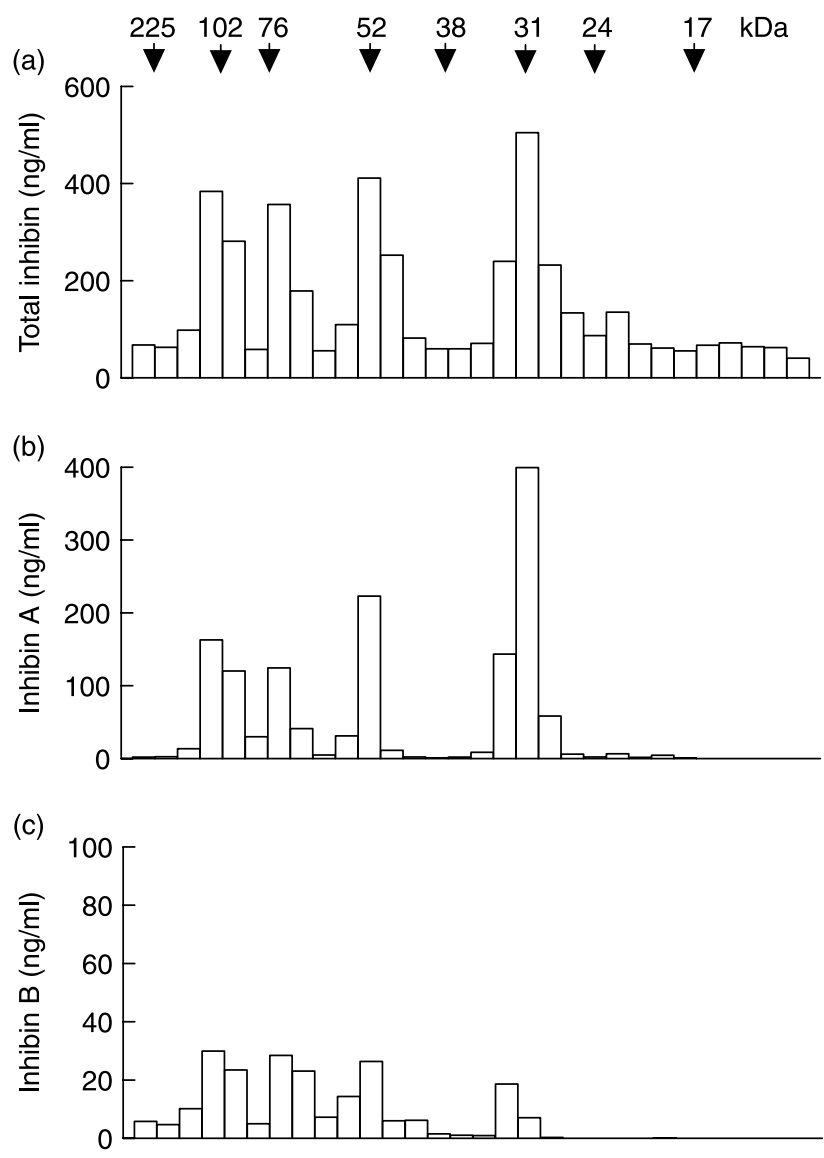

Figure 1 Molecular weight distributions of (a) total inhibin, (b) inhibin $A$, and (c) inhibin B in eluates from gel slices after fractionation of pFF by immunoaffinity chromatography and SDS-PAGE. Molecular weights and positions of marker proteins used to calibrate the gels are denoted at the top.

\section{Validation of ultrasonic measurements of follicular diameters}

There was a linear relationship between the diameter of follicles measured by ultrasonography $(x)$ and the diameter of the same follicles after dissection from the ovary $(y)$. The regression was $y=0.97 x+0.79(r=0.975$, $P<0.01)$.

\section{Growth and regression of follicles and corpora lutea during the estrous cycle}

Mean diameter of the largest corpora lutea (CLs) was smaller on days -6 and -5 than on day -10 , and CLs were not identified from days -4 to 1 (Fig. 2a). On day 2 , formation of CLs was observed in all sows, and the $\mathrm{CL}$ diameter markedly increased thereafter. Each sow showed increases in the total number of follicles $(\geq 3 \mathrm{~mm}$ in diameter) between the late luteal and the follicular phases and in the early luteal phase (Supplementary Figure 1, see section on supplementary data given at end of this article). The mean number of 

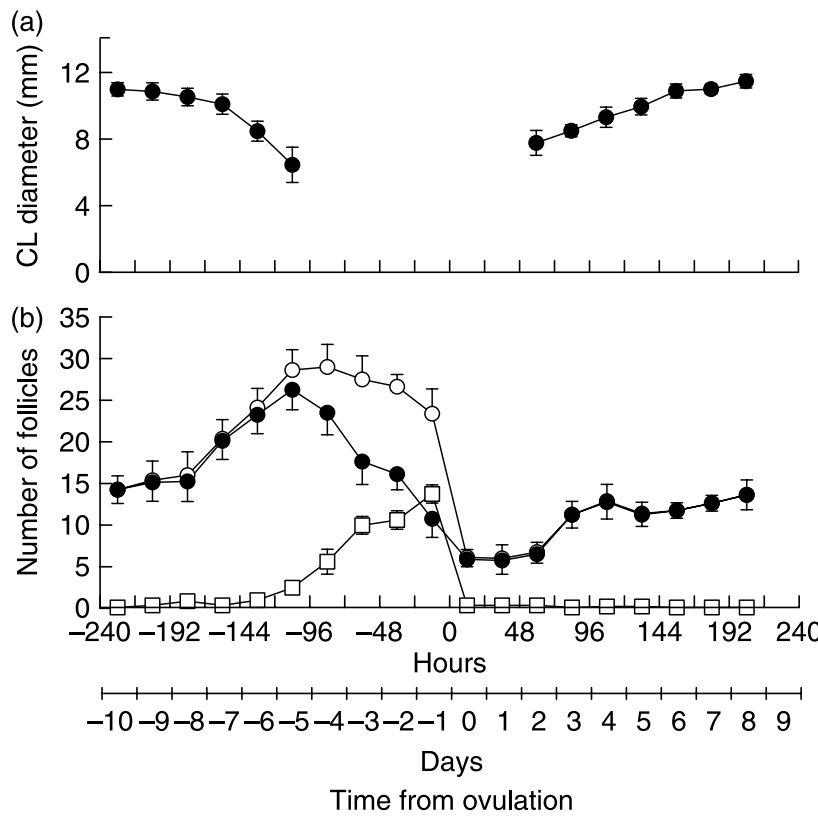

Figure 2 Development and regression of maximum-sized corpora lutea (CLs) (a), and (b) changes in the numbers of small (closed circles), large (open squares), and all (open circles) follicles during the estrous cycle of pigs. Values are means \pm s.E.M. $(n=8)$. Daily ultrasonographic data are aligned relative to detection of ovulation on the basis of $6 \mathrm{~h}$ interval scanning (ovulation=hour 0 ).

small follicles ( $\geq 3$ and $<6 \mathrm{~mm}$ in diameter) obtained from eight sows was significantly greater $(P<0.05)$ on day $-5(26.3 \pm 2.4$, mean \pm s.E.M. $)$ than on day -10 $(14.3 \pm 1.7)$; on day -4 , it was approximately the same as on day -5 . By day -2 , there were significantly $(P<0.05)$ fewer small follicles $(16.1 \pm 1.9)$ than on day -5 , and the number had further declined by day $0(5.9 \pm 0.9)$ (Fig. $2 b)$. By day 4 , the number of small follicles $(12.8 \pm 2.0)$ was significantly $(P<0.05)$ greater than on day 0 , but it showed no significant changes thereafter. Large follicles ( $\geq 6 \mathrm{~mm}$ in diameter) were rare between days -10 and -6 , but between days -4 and -1 their numbers were significantly $(P<0.05)$ greater than on day $-6(0.9 \pm 0.5)$. After an abrupt decrease from days $-1(13.6 \pm 1.1)$ to 0 $(0.3 \pm 0.2)$, indicating ovulation, there was no increase in the number of large follicles. The pattern of change in the total number of follicles was similar to that of small follicles on all days, except between days -3 and -1 , when many large follicles appeared.

\section{Plasma concentrations of dimeric inhibins and total inhibin}

In each sow, plasma concentrations of inhibin A and total inhibin showed a transient increase in the early luteal phase in addition to an increase during the follicular phase (Supplementary Figure 1), although the duration of the rises varied. The mean concentration of inhibin A was significantly greater $(P<0.05)$ on day $-7(141.6$ $\pm 11.2 \mathrm{pg} / \mathrm{ml})$ than on day $-10(72.4 \pm 12.0 \mathrm{pg} / \mathrm{ml})$ and remained $>110 \mathrm{pg} / \mathrm{ml}$ until day -3 (Fig. 3a), with the exception of a drop on day -6 . In association with the onset of the preovulatory LH surge on day -2 , inhibin A levels on day $-3(132.9 \pm 18.3 \mathrm{pg} / \mathrm{ml})$ dropped significantly $(P<0.05)$ to the much lower value of 46.7 $\pm 9.6 \mathrm{pg} / \mathrm{ml}$ by day -1 . On days 3 and 5 , inhibin A levels were significantly greater $(P<0.05)$ than those on day 1 (the lowest value; $46.2 \pm 8.8 \mathrm{pg} / \mathrm{ml}$ ); thereafter, they did not change significantly. Plasma concentrations of total inhibin were generally double the inhibin A concentrations (Fig. 3a), to which they were positively related throughout the estrous cycle $(r=0.46, P<0.01)$ : there were two significant rises in total inhibin level: between days -7 and -2 (excluding days -6 and -5 ) compared with the value on day -10 , and on days 3 and 4 compared with the lowest value on day 0 . Inhibin B levels in the circulation were below the detection limit of the assay.

\section{Plasma concentrations of $E_{2}$, progesterone, $F S H$, and $\mathrm{LH}$}

Concentrations of $\mathrm{E}_{2}$ were significantly greater $(P<0.05)$ on day $-5(7.9 \pm 1.1 \mathrm{pg} / \mathrm{ml})$ than on days -10 and -7 , and they continued to increase until day -3 . By day -1 ,
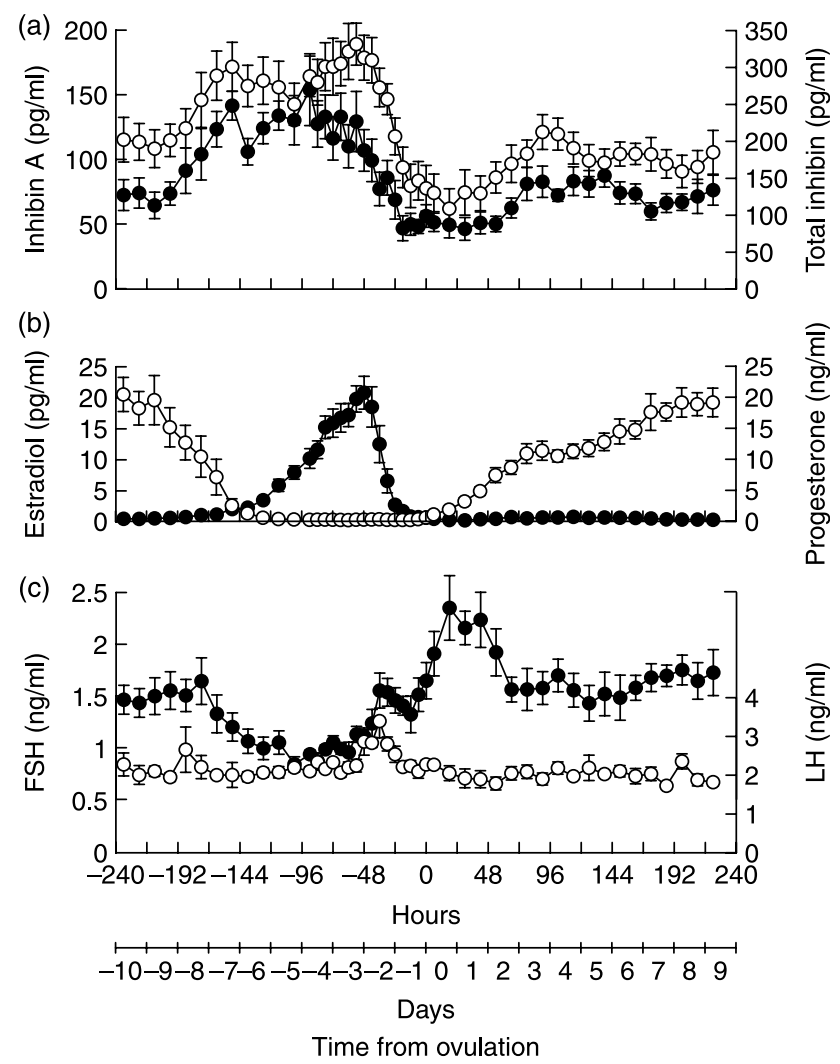

Figure 3 Plasma concentrations of (a) inhibin A (closed circles) and total inhibin (open circles), (b) estradiol (closed circles) and progesterone (open circles), and (c) FSH (closed circles) and LH (open circles) during the estrous cycle of pigs. Values are means \pm s.E.M. $(n=8)$. Hormonal data are aligned relative to detection of ovulation on the basis of $6 \mathrm{~h}$ interval scanning (ovulation $=$ hour 0 ). 
$\mathrm{E}_{2}$ levels dropped significantly $(P<0.05)$ to $1 \mathrm{pg} / \mathrm{ml}$ from the day -2 value $(20.8 \pm 2.6 \mathrm{pg} / \mathrm{ml})$. There was no significant increase in plasma $E_{2}$ after ovulation. Plasma progesterone levels began to decrease from day -7 compared with the values on day -10 and were at their minimum between days -5 and -1 . After ovulation, they began to rise from day 0 and plateaued on day 7 .

Concentrations of $\mathrm{FSH}$ in the plasma were $\sim 1.5 \mathrm{ng} / \mathrm{ml}$ between days -10 and -8 . FSH levels then decreased significantly $(P<0.05)$ between days -6 and -3 compared with the value on day -8 (Fig. 3c), but they showed a small but significant increase after detection of estrus (day -2 ). In the 2 days after ovulation (days 0 and 1 ), a high FSH concentration (peak value $2.3 \mathrm{ng} / \mathrm{ml}$ ) was noted, but the value had declined significantly $(P<0.05)$ by day 3 . The FSH level then showed no significant changes. The LH concentration showed a clear $(P<0.05)$ peak on day -1 , but there were no significant changes during the rest of the cycle. An inverse relationship was found between the levels of $\mathrm{FSH}$ and inhibin from days -10 to -3 (inhibin A, $r=-0.47, P<0.01$; total inhibin, $r=-0.38$, $P<0.01$ ) and from days 0 to 9 (inhibin $A, r=-0.42$, $P<0.01$; total inhibin, $r=-0.38, P<0.01)$. There was also an inverse relationship between $\mathrm{FSH}$ and $\mathrm{E}_{2}$ levels between days -10 and $-3 \quad(r=-0.38, P<0.01)$; however, there was no significant correlation between the two hormones from days 0 to $9(r=-0.12, P \geq 0.1)$.

\section{Discussion}

Our most important findings were that 1) in terms of specificity and sensitivity, our Tr-IFMA was applicable to measurement of porcine inhibin A in the circulation; and 2) circulating levels of inhibin A were inversely correlated with FSH levels during the follicular growth that occurred between the late luteal and follicular phases of the porcine estrous cycle and during the early luteal phase.

IFMA and FIA recognized 30, 50, 72, and $108 \mathrm{kDa}$ molecules in the eluates obtained from pFF after immunoaffinity chromatography. These are likely to correspond to the higher molecular weight precursor forms of inhibin $\mathrm{A}$, in addition to fully processed $32 \mathrm{kDa}$ inhibin $\mathrm{A}$, as previously described in porcine (Miyamoto et al. 1986) and bovine follicular fluid (FF; Sugino et al. 1992). Early studies have demonstrated the existence of high concentrations of a $26 \mathrm{kDa}$-free $\alpha$ subunit (pro- $\alpha \mathrm{C}$ ) in bovine FF (Knight et al. 1989, Robertson et al. 1989, Sugino et al. 1989) and in the circulation (Knight et al. 1989). However, inhibin A IFMA detected little immunoreactivity around the $26 \mathrm{kDa}$ fractions obtained from $\mathrm{pFF}$. The results suggested that $26 \mathrm{kDa}$ pro- $\alpha \mathrm{C}$ does not interfere with porcine inhibin A IFMA. Measurement of dimeric inhibins in the fractions of pFF also clearly indicated that porcine follicles produced largely inhibin A, although smaller amounts of inhibin B were synthesized. These results are consistent with the previous finding that inhibin $\beta_{\mathrm{A}}$ mRNA expression in porcine follicles is higher than that of the $\beta_{\mathrm{B}}$ subunit (Li et al. 1997). As in cows (Bleach et al. 2001, Kaneko et al. 2002a, Kaneko \& Hasegawa 2007), ewes (Knight et al. 1998), and female goats (Medan et al. 2003), in sows the inhibin isoform detectable in the circulation is inhibin $\mathrm{A}$; this is in contrast to the case in women (Groome et al. 1996,) and female rats (Woodruff et al. 1996), in which both inhibin A and B circulate in the peripheral blood.

To our knowledge, this is the first report to describe the correlation between circulating inhibin $\mathrm{A}$ and plasma FSH levels and follicular dynamics throughout the pig estrous cycle. An increase in the concentration of plasma inhibin A occurred at the same time as the increase in the number of small follicles between the late luteal and follicular phases and during the early luteal phase. A clear inverse relationship between plasma inhibin $\mathrm{A}$ and $\mathrm{FSH}$ existed in these two periods, whereas $E_{2}$ levels showed no increase and no relationship with FSH concentrations during the early luteal phase. The results are consistent with the detection of relatively constant levels of mRNAs encoding inhibin $\alpha$ and $\beta_{\mathrm{A}}$ subunits in follicles $1 \mathrm{~mm}$ or more in diameter (Guthrie et al. 1992, Garrett et al. 2000); expression of aromatase mRNA dramatically increases once the follicles reach $6 \mathrm{~mm}$ in diameter (Liu et al. 2000). Consideration of these findings in combination with the finding that treatment of pigs with inhibin preparations decreases FSH secretion (Guthrie et al. 1987, 1988, Knox et al. 1991, Knox \& Zimmerman 1993, Bracken et al. 2006) strongly suggests that inhibin A acts as a feedback regulator of $\mathrm{FSH}$ throughout the porcine estrous cycle; in contrast, $E_{2}$ has inhibitory effects only during the follicular phase.

The $\mathrm{CL}$ of the human and other primates produces large amounts of inhibin-free $\alpha$ subunits (Knight et al. 1992) in addition to inhibin A (Schwall et al. 1990, Roberts et al. 1993), and high concentrations of total inhibin and inhibin $A$ have been noted during the mid-luteal phase of the menstrual cycle (Groome et al. 1994, 1996). We found no parallel changes between the plasma concentrations of total inhibin and inhibin A and those of progesterone. The porcine $\mathrm{CL}$ does not seem to secrete substantial amounts of inhibins into the circulation.

In our ultrasonographic examinations, mean number of small follicles ( $\geq 3$ and $<6 \mathrm{~mm}$ in diameter) detected during the late luteal phase ranged from 20 to 26 , which is less than the number (40-50) of the same-sized follicles previously determined by macroscopic measurements (Clark et al. 1975, Guthrie et al. 1995b). One possible reason for this difference is the fact that our ultrasonographic estimates of follicle size were about $0.7 \mathrm{~mm}$ smaller than the macroscopic measurements, 
probably because only the antral cavities (i.e. the anechoic regions) of the follicles were measured by the ultrasound scanner. When we rearranged our ultrasonographic data collected during the late luteal phase, the number of follicles $\geq 2$ and $<5 \mathrm{~mm}$ in diameter, which corresponds approximately to follicles $\geq 3$ and $<6 \mathrm{~mm}$ in actual diameter, ranged from $32.4 \pm 4.9(n=8)$ to $35.8 \pm 3.8(n=8)$. These follicle numbers are $75-80 \%$ of those reported in the previous studies (Clark et al. 1975, Guthrie et al. 1995b); they are similar to those given in a recent study in which $\sim 80 \%$ of follicles between 2 and $4 \mathrm{~mm}$ in diameter were detectable by ultrasonography (Gonzarez-Añover et al. 2009). Differences in breeds and nutritional conditions between our study and these previous ones may also have affected the number of follicles in the ovary.

Although with ultrasonography not all of the follicles present in the ovary are detectable, our follicle counts, in combination with the changes in plasma inhibin and FSH levels, demonstrated that a group of follicles grew during the early luteal phase and in the late luteal to follicular phases. Follicular growth before ovulation was wave like; it was characterized by the appearance of a cohort of follicles of 3-6 mm in diameter, of which at least 10-17 continued to grow as co-dominant follicles, reaching ovulation while the others regressed, as described in previous reports (Clark et al. 1975, Kelly et al. 1988a, Guthrie \& Bolt 1990, Ryan et al. 1994). The high concentrations of FSH that we observed in the mid-luteal phase are likely to stimulate follicle emergence from the late luteal to the follicular phases. These follicles are likely to lower the plasma FSH level by increasing their secretion of inhibin A and, subsequently, $\mathrm{E}_{2}$; thereby, they initiate follicle selection within their own group and suppress the growth of new follicles.

However, there have been controversial findings with regard to the presence of synchronous growth of follicles during the early luteal phase in pigs. Several studies based on counts of the number of follicles in the ovary (Clark et al. 1975, Kelly et al. 1988a) or ultrasound observations of the ovary (Ryan et al. 1994) have suggested that there is no wave-like follicular growth during the luteal phase, apart from the ovulatory follicular wave that appears in the late luteal phase. In contrast, Dalin (1987) showed a trend toward a follicular wave between days 6 and 8 after estrus. We found that the mean concentrations of inhibin $A$ and total inhibin were clearly elevated in the early luteal phase, concomitant with an increase in the number of follicles $3-5 \mathrm{~mm}$ in diameter. Combined with the previous findings that mRNAs encoding inhibin $\alpha$ and $\beta_{A}$ subunits are expressed in follicles with diameters of $1 \mathrm{~mm}$ or more (Guthrie et al. 1992, Garrett et al. 2000), our findings support the presence of synchronous growth of follicles during the early luteal phase. The fate of these new follicles is not clear from the mean inhibin profiles, because these profiles showed no significant changes following the transient rise on days 3 and 4 . However, analysis of inhibin profiles during the early luteal phase in individual sows indicated that inhibin A and total inhibin showed an elevation around days 3-6 but declined by day 7 as shown in Supplementary Figure 1. Biochemical classification of follicle groups has revealed that most follicles 3-5 mm in diameter are nonatretic on day 5 after estrus in pigs, but that the incidence of follicular atresia increases by day 7 (Guthrie et al. 1995a, 1995b). Our inhibin data obtained from each sow, together with the data from these previous biochemical analyses of follicles, suggest that new, small follicles seem to become atretic without further growth, probably because of lowered LH pulse frequency (Flowers et al. 1991, Estienne et al. 1998, Ferguson et al. 2003) under high progesterone levels, because high LH pulse frequency is necessary for continued growth of follicles (Esbenshade et al. 1990, Lucy et al. 2001).

The typical follicular wave, for example in cattle, is defined as the synchronous growth of a cohort of follicles, one of which continues to grow to a dominant follicle while the others regress (Evans 2003). During the early luteal phase of the porcine estrous cycle, growth of ovulatory-sized follicles is absent (this study plus those of Clark et al. (1975), Kelly et al. (1988a) and Ryan et al. (1994)). However, our data indicate that the cohort of small follicles, the growth of which is stimulated by the secondary FSH surge, has the ability to produce inhibin A and is likely to exert an influence over less mature follicles by lowering FSH secretion. This is similar to the influence proposed for dominant follicles in ruminants (Ko et al. 1991, Adams et al. 1992). Follicular growth during the early luteal phase in pigs may be functionally analogous to the wave during the early luteal phase of cows (Bleach et al. 2001, Kaneko et al. 2002a).

To summarize, combined analyses of plasma inhibin A and follicular dynamics revealed two periods of follicle emergence during the porcine estrous cycle. A reciprocal relationship exists between the patterns of secretion of inhibin A and FSH during each follicle emergence, indicating that inhibin $\mathrm{A}$ is a primary feedback hormone for $\mathrm{FSH}$ in pigs.

\section{Materials and Methods}

\section{Animals}

Protocols for the use of animals were approved by the Institutional Care and Use Committee for Laboratory Animals of the National Institute of Animal Health, Tsukuba, Japan. Eight sows (crossbreeds of Landrace $\times$ Large White, purchased from Cimco, Tokyo, Japan), weighing $212.8 \pm 7.3 \mathrm{~kg}$ (mean \pm s.E.M.) and aged $23.3 \pm 1.6$ months, were used. Mean length of their estrous cycles was $21.3 \pm 0.3$ days ( $n=11$ cycles). 


\section{Ovarian examination and blood samplings}

Ovaries of sows were scanned daily transrectally with an ultrasound scanner (SSD-900SE, Aloka, Tokyo, Japan) with a 7.5 MHz linear array transducer, starting 10 days after the previous ovulation and ending 10 days after the subsequent ovulation. During examination, images of ovarian structures were recorded on a digital video recorder (MOVIE VISION, System TALKS, Tokyo, Japan). Follicles were identified as anechoic spherical structures; the diameters of follicles $2 \mathrm{~mm}$ or more in diameter, and CLs, were measured. Follicles were classified by size as small ( $\geq 3$ and $<6 \mathrm{~mm}$ in diameter) or large ( $\geq 6 \mathrm{~mm}$ in diameter), because $E_{2}$ production is much higher in follicles at least $6 \mathrm{~mm}$ in diameter than in smaller follicles (van de Wiel et al. 1983, Kita et al. 1994, Shores \& Hunter 1999, Liu et al. 2000). Growth and regression of CLs were expressed in terms of the mean diameter of the largest $\mathrm{CL}$ in each sow on each day. In addition, after sows had been deemed to be in estrus (as defined in 6-hourly observations by their first standing response to an intact boar), the ovaries were scanned at $6 \mathrm{~h}$ intervals to detect ovulation. Ovulation was defined as the time when there was a marked reduction in the number of large follicles relative to that in previous observations (Knox \& Probst-Miller 2004).

Blood samples were collected every $12 \mathrm{~h}$ throughout the study via an indwelling catheter in the auricular vein, and every $6 \mathrm{~h}$ from 17 days after the previous ovulation to the end of the subsequent estrus, to characterize hormonal profiles during the periovulatory period. Plasma was recovered after centrifugation of blood and stored at $-20^{\circ} \mathrm{C}$.

\section{Validation of ultrasonographic measurements of follicular diameter}

Porcine ovaries obtained from a local abattoir were scanned in a water bath, and the diameters of 41 follicles were recorded. These follicles were dissected from the ovaries and their diameters were measured by a metallic calliper. Then we compared the diameters of follicles measured by ultrasonography with the diameters of the same follicles after dissection.

\section{Time-resolved FIA of porcine total inhibin}

Concentrations of total inhibin were determined by a competitive immunoassay using europium (Eu)-labeled bovine inhibin A as a probe (Kaneko et al. 2002 b, Ohnuma et al. 2007). In timeresolved FIA ( Tr-FIA) of porcine total inhibin, anti-bovine inhibin serum (TNDH-1, Hamada et al. 1989), provided by Dr K Taya of Tokyo University of Agriculture and Technology, Fuchu, Tokyo, Japan, was used as a primary antibody. Porcine $30 \mathrm{kDa}$ inhibin A, purified from pFF by the method of Hasegawa et al. (1994), was used as a reference standard. The detection limit of the assay was $0.039 \mathrm{ng} / \mathrm{ml}$. When total inhibin was measured in a plasma sample $(100 \mu \mathrm{l})$, serum from an ovariectomized gilt $(100 \mu \mathrm{l})$ was added to each well of the standards to correct for the matrix effects of porcine plasma. Fluorescence was measured with a fluorometer (Arvo, PerkinElmer Japan, Yokohama, Kanagawa, Japan). The intra- and inter-assay coefficients of variation $(\mathrm{CV})$ were 10.7 and $15.8 \%$, respectively.

\section{Tr-IFMA of porcine inhibin A}

Concentrations of inhibin A were determined by Tr-IFMA using purified polyclonal antibodies to the $\alpha$ and $\beta_{\mathrm{A}}$ subunits of bovine inhibin $\mathrm{A}$, as described previously (Kaneko et al. 2002a). Porcine $30 \mathrm{kDa}$ inhibin A was used as a reference standard. Inhibin A IFMA shows very low cross-reactivity $(<1 \%)$ with porcine inhibin $B$, bovine activin $A$, bovine activin $B$, bovine activin $A B$, and bovine pro- $\alpha C$ when the crossreactivity with porcine inhibin $A$ is calculated to be $100 \%$ (Ohnuma et al. 2007). The detection limit of the assay was $10 \mathrm{pg} / \mathrm{ml}$. When inhibin A was measured in plasma samples $(100 \mu \mathrm{l})$, serum from an ovariectomized gilt $(100 \mu \mathrm{l})$ was added to each well of the standards to correct for the matrix effects of porcine plasma. Serial dilution of plasma samples showed a dose-response curve that paralleled a standard curve generated with porcine inhibin A. The intra- and inter-assay CV were 9.7 and $15.1 \%$, respectively.

\section{Tr-IFMA of porcine inhibin B}

Concentrations of inhibin B were determined by Tr-IFMA, as described previously (Kaneko et al. 2003). Porcine $29 \mathrm{kDa}$ inhibin B, purified from pFF by the method of Hasegawa et al. (1994), was used as a reference standard. Inhibin B IFMA shows very low cross-reactivity $(<2 \%)$ with porcine inhibin $A$, bovine activin $A$, bovine activin $B$, bovine activin $A B$, and bovine pro- $\alpha \mathrm{C}$ (Ohnuma et al. 2007). The detection limit of the assay was $0.78 \mathrm{ng} / \mathrm{ml}$. The intra- and inter-assay CV were 11.7 and $16.8 \%$, respectively.

\section{Isolation of inhibin molecules from pFF}

To determine whether different molecular weight forms of inhibin cross-react in the FIA or IFMAs, $6 \mu \mathrm{g}$ inhibin, purified from pFF by immunoaffinity chromatography, was fractionated by SDS-PAGE as described previously (Kaneko et al. 2002a, 2003). Antiserum used for immunoaffinity chromatography was raised against bovine $32 \mathrm{kDa}$ inhibin (Kaneko et al. 1993) and cross-reacting inhibin $\alpha$ subunits (Kaneko et al. 2002a, 2003, Ohnuma et al. 2007). The gel was cut into $2.0 \mathrm{~mm}$ slices. Under gentle shaking overnight, inhibin was extracted from each gel slice with Tris-buffered saline $(0.05 \mathrm{M}$ Tris/ $\mathrm{HCl}(\mathrm{pH} 7.5)$ and $0.15 \mathrm{M} \mathrm{NaCl})$ containing $5 \mathrm{mM}$ EDTA. The gel eluates were assayed for total inhibin by FIA and for inhibin A and B by IFMA.

\section{Tr-FIA of porcine $\mathrm{FSH}, \mathrm{LH}, \mathrm{E}_{2}$, and progesterone}

Concentrations of $\mathrm{FSH}$ or $\mathrm{LH}$ in plasma of sows were determined by competitive immunoassays using Eu-labeled FSH (Kaneko et al. 2002a, Ohnuma et al. 2007) or LH (Noguchi et al. 2007) as probes. In the FIA of porcine FSH, anti-porcine FSH serum (AFP-2062096) was used as a primary antibody and porcine FSH antigen (AFP-10640B) was used for Eu labeling and as a reference standard. In the FIA of porcine $\mathrm{LH}$, antiporcine LH antibody (AFP15103194Rb) was used as a primary antibody and porcine LH (AFP11043B) was used for Eu labeling 
and as the reference standard. Porcine $\mathrm{FSH}$ and $\mathrm{LH}$ immunoassay kits were provided by $\mathrm{Dr}$ A $\mathrm{F}$ Parlow of the National Hormone and Peptide Program, Harbor-UCLA Medical Center, Torrance, CA, USA. The respective intra- and inter-assay $\mathrm{CV}$ were 7.2 and $10.0 \%$ for $\mathrm{FSH}$ and 6.8 and $8.4 \%$ for $\mathrm{LH}$.

Plasma concentrations of $\mathrm{E}_{2}$ and progesterone were measured with a Tr-FIA kit (DELFIA Estradiol and Progesterone kits, PerkinElmer Japan), as previously reported (Noguchi et al. 2007). $E_{2}$ and progesterone were extracted from the plasma samples with diethyl ether before being applied to the kits. The respective intra- and inter-assay $C V$ were 8.4 and $11.0 \%$ for $E_{2}$ and 7.8 and $7.2 \%$ for progesterone.

\section{Data analyses}

In order to correlate hormonal profiles with follicular growth, data were aligned relative to the detection of ovulation on the basis of $6 \mathrm{~h}$ interval scanning (ovulation=hour 0 ). The estrous cycle was divided into the two periods: before ovulation (days -10 to 0 ) and after ovulation (days 0-9). Data pertaining to follicular growth and hormonal profiles in each period were subjected to ANOVA for repeated measures (Glantz \& Slinker 1990). When a significant effect was detected by ANOVA, the significance of the difference between means was determined by Tukey's test. Regression analyses among inhibin, $\mathrm{E}_{2}$, and $\mathrm{FSH}$ concentrations were also performed. All data were analyzed by using the General Linear Models or REG Procedure of Statistical Analysis Systems (SAS Inc., Cary, NC, USA). A value of $P<0.05$ was considered to indicate statistical significance.

\section{Supplementary data}

This is linked to the online version of the paper at http://dx.doi. org/10.1530/REP-09-0018.

\section{Declaration of interest}

The authors declare that there is no conflict of interest that would prejudice the impartiality of this scientific work.

\section{Funding}

This work was supported in part by a Grant-in-Aid for Scientific Research from the Japanese Society for the Promotion of Science (JSPS) to $\mathrm{H}$ Kaneko (21380175) and by a JSPS Fellowship to M Noguchi $(21 \cdot 2844)$.

\section{Acknowledgements}

We thank Dr K Taya, Laboratory of Veterinary Physiology, Tokyo University of Agriculture and Technology, Fuchu, Tokyo 183-0054, Japan, for providing anti-bovine inhibin serum (TNDH-1) for the FIA. We also thank Dr A F Parlow, National Hormone and Peptide Program of National Institute of Diabetes and Digestive and Kidney Diseases, Harbor-UCLA Medical Center, Torrance, CA, for providing the porcine FSH and $\mathrm{LH}$ immunoassay kits.

\section{References}

Adams GP, Matteri RL, Kastelic JP, Ko JC \& Ginther OJ 1992 Association between surges of follicle-stimulating hormone and the emergence of follicular waves in heifers. Journal of Reproduction and Fertility 94 177-188.

Bleach EC, Glencross RG, Feist SA, Groome NP \& Knight PG 2001 Plasma inhibin A in heifers: relationship with follicle dynamics, gonadotropins, and steroids during the estrous cycle and after treatment with bovine follicular fluid. Biology of Reproduction 64 743-752.

Bracken CJ, Radcliff RP, McCormack BL, Keisler DH \& Lucy MC 2006 Decreased follicular size during late lactation caused by treatment with charcoal-treated follicular fluid delays onset of estrus and ovulation after weaning in sows. Journal of Animal Science 84 2110-2117.

Clark JR, First NL, Chapman AB \& Casida LE 1975 Ovarian follicular development during the estrous cycle in gilts following electrocautery of follicles. Journal of Animal Science 41 1105-1111.

Dalin AM 1987 Ovarian follicular activity during the luteal phase in gilts. Journal of Veterinary Medicine A 34 592-601.

Esbenshade KL, Ziecik AJ \& Britt JH 1990 Regulation and action of gonadotrophins in pigs. Journal of Reproduction and Fertility Supplement 40 19-32.

Estienne MJ, Hurlock WF \& Barb CR 1998 Serum concentrations of luteinizing hormone, growth hormone, and cortisol in gilts treated with $\mathrm{N}$-methyl-D,L-aspartate during the estrous cycle or after ovariectomy. Journal of Animal Science 76 2162-2168.

Evans ACO 2003 Characteristics of ovarian follicle development in domestic animals. Reproduction in Domestic Animals 38 240-246.

Fahy PA, Wilson CA, Beard AJ, Groome NP \& Knight PG 1995 Changes in inhibin-A (alpha-beta A dimer) and total alpha inhibin in the peripheral circulation and ovaries of rats after gonadotrophin-induced follicular development and during the normal oestrous cycle. Journal of Endocrinology 147 271-283.

Ferguson EM, Ashworth CJ, Edwards SA, Hawkins N, Hepburn N \& Hunter MG 2003 Effect of different nutritional regimens before ovulation on plasma concentrations of metabolic and reproductive hormones and oocyte maturation in gilts. Reproduction 126 61-71.

Flowers B, Cantley TC, Martin MJ \& Day BN 1991 Episodic secretion of gonadotrophins and ovarian steroids in jugular and utero-ovarian vein plasma during the follicular phase of the oestrous cycle in gilts. Journal of Reproduction and Fertility 91 101-112.

Fukuda M, Miyamoto K, Hasegawa Y, Nomura M, Igarashi M, Kangawa K \& Matsuo H 1986 Isolation of bovine follicular fluid inhibin of about 32 kDa. Molecular and Cellular Endocrinology 44 55-60.

Garrett WM, Mack SO, Rohan RM \& Guthrie HD 2000 In situ analysis of the changes in expression of ovarian inhibin subunit mRNAs during follicle recruitment after ovulation in pigs. Journal of Reproduction and Fertility 118 235-242.

Ginther OJ, Kot K \& Wiltbank MC 1995 Associations between emergence of follicular waves and fluctuations in $\mathrm{FSH}$ concentrations during the estrous cycle in ewes. Theriogenology 43 689-703.

Glantz SA \& Slinker BK 1990 Repeated measures. In Primer of Applied Regression and Analysis of Variance, pp 381-463. Eds SA Glantz \& BK Slinker. New York: McGraw-Hill.

Gonzalez-Añover P, Encinas T, Gomez-Izquierdo E, Sanz E, SanchezSanchez R \& Gonzalez-Bulnes A 2009 Accuracy of in vivo and ex vivo ultrasonographic evaluation of ovarian follicles and corpora lutea in sows. Theriogenology 71 1433-1439.

Groome NP, Illingworth PJ, O'Brien M, Cooke I, Ganesan TS, Baird DT \& McNeilly AS 1994 Detection of dimeric inhibin throughout the human menstrual cycle by two-site enzyme immunoassay. Clinical Endocrinology 40 717-723.

Groome NP, Illingworth PJ, O'Brien M, Pai R, Rodger FE, Mather JP \& McNeilly AS 1996 Measurement of dimeric inhibin B throughout the human menstrual cycle. Journal of Clinical Endocrinology and Metabolism 81 1401-1405.

Guthrie HD \& Bolt DJ 1990 Changes in plasma follicle-stimulating hormone, luteinizing hormone, estrogen and progesterone during growth of ovulatory follicles in the pig. Domestic Animal Endocrinology 7 83-91.

Guthrie HD, Bolt DJ, Kiracofe GH \& Miller KF 1987 Effect of charcoalextracted porcine follicular fluid and 17 beta-estradiol on follicular growth and plasma gonadotropins in gilts fed a progesterone agonist, altrenogest. Journal of Animal Science 64 816-826. 
Guthrie HD, Bolt DJ, Kiracofe GH \& Miller KF 1988 Ovarian response to injections of charcoal-extracted porcine follicular fluid and porcine follicle-stimulating hormone in gilts fed a progesterone agonist (altrenogest). Biology of Reproduction 38 750-755.

Guthrie HD, Rohan RM, Rexroad CE Jr \& Cooper BS 1992 Changes in concentrations of follicular inhibin $\alpha$ and $\beta A$ subunit messenger ribonucleic acids and inhibin immunoactivity during preovulatory maturation in the pig. Biology of Reproduction 47 1018-1025.

Guthrie HD, Cooper BS, Welch GR, Zakaria AD \& Johnson LA 1995 a Atresia in follicles grown after ovulation in the pig: measurement of increased apoptosis in granulose cells and reduced follicular fluid estradiol-17 $\beta$. Biology of Reproduction 52 920-927.

Guthrie HD, Grimes RW, Cooper BS \& Hammond JM 1995b Follicular atresia in pigs: measurement and physiology. Journal of Animal Science 73 2834-2844.

Hamada T, Watanabe G, Kokuho T, Taya K, Sasamoto S, Hasegawa Y, Miyamoto K \& Igarashi M 1989 Radioimmunoassay of inhibin in various mammals. Journal of Endocrinology 122 697-704.

Hasegawa Y, Miyamoto S, Iwamura S \& Igarashi M 1988 Changes in serum concentrations of inhibin in cyclic pigs. Journal of Endocrinology 118 211-219.

Hasegawa Y, Miyamoto K, Sugino H, Takio K, Inoue M \& Ibuki Y 1994 Progress with human and rat inhibin characterization. In Inhibin and Inhibin-Related Proteins, pp 5-24. Eds HG Burger, J Findlay, D Robertson, D de Kretser \& F Petraglia. Rome: Ares-Serono Symposia Publications.

Hasegawa Y, Madarame T, Yoshida S, Kaneko H, Abe Y, Mizunuma H \& Ibuki Y 1997 Two-site immunoassay for native inhibin A. In Inhibin, Activin, and Follistatin: Regulatory Functions in System and Cell Biology, pp 104-117. Eds TAono, H Sugino \& WW Vale. New York: Springer-Verlag.

Kaneko H \& Hasegawa Y 2007 Application of time-resolved fluorometry to immunoassays for bovine reproductive hormones. Animal Science Journal 78 7-15.

Kaneko H, Nakanishi Y, Taya K, Kishi H, Watanabe G, Sasamoto S \& Hasegawa $Y 1993$ Evidence that inhibin is an important factor in the regulation of $\mathrm{FSH}$ secretion during the mid-luteal phase in cows. Journal of Endocrinology 136 35-41.

Kaneko H, Noguchi J, Kikuchi K, Todoroki J \& Hasegawa Y 2002a Alterations in peripheral concentrations of inhibin $\mathrm{A}$ in cattle studied using a time-resolved immunofluorometric assay: relationship with estradiol and follicle-stimulating hormone in various reproductive conditions. Biology of Reproduction 67 38-45.

Kaneko H, Todoroki J, Noguchi J, Kikuchi K, Mizoshita K, Kubota C \& Yamakuchi H 2002b Perturbation of estradiol-feedback control of luteinizing hormone secretion by immunoneutralization induces development of follicular cysts in cattle. Biology of Reproduction 67 1840-1845.

Kaneko H, Noguchi J, Kikuchi K \& Hasegawa Y 2003 Molecular weight forms of inhibin A and inhibin B in the bovine testis change with age. Biology of Reproduction 68 1918-1925.

Kaneko H, Matsuzaki M, Noguchi J, Kikuchi K, Ohnuma K \& Ozawa M 2006 Changes in circulating and testicular levels of inhibin A and B during postnatal development in bulls. Journal of Reproduction and Development 52 741-749.

Kelly CR, Kopf JD \& Zimmerman DR 1988a Characterization of antral follicle populations during the estrous cycle in pigs selected for ovulation rate. Journal of Animal Science 66 1230-1235.

Kelly CR, Socha TE \& Zimmerman DR 1988b Characterization of gonadotropic and ovarian steroid hormones during the periovulatory period in high ovulating select and control line gilts. Journal of Animal Science 66 1462-1474.

Kita M, Taii S, Kataoka N, Shimatsu A, Nakao K \& Mori T 1994 Changes of gonadotrophin surge inhibiting/attenuating factor activity in pig follicular fluid in relation to follicle size. Journal of Reproduction and Fertility 101 59-66.

Knight PG, Beard AJ, Wrathall JH \& Castillo RJ 1989 Evidence that the bovine ovary secretes large amounts of monomeric inhibin alpha subunit and its isolation from bovine follicular fluid. Journal of Molecular Endocrinology 2 189-200.

Knight PG, Muttukrishna S, Groome N \& Webley GE 1992 Evidence that most of the radioimmunoassayable inhibin secreted by the corpus luteum of the common marmoset monkey is of a non-dimeric form. Biology of Reproduction 47 554-560.
Knight PG, Feist SA, Tannetta DS, Bleach EC, Fowler PA, O'Brien M \& Groome NP 1998 Measurement of inhibin-A (alpha beta A dimer) during the oestrous cycle, after manipulation of ovarian activity and during pregnancy in ewes. Journal of Reproduction and Fertility 113 159-166.

Knox RV \& Probst-Miller A 2004 Evaluation of transrectal ultrasonograhy for use in identifying sources of reproductive in wean sows. Journal of Swine Health and Production 12 71-74.

Knox RV \& Zimmerman DR 1993 Effect of administration of porcine follicular fluid to gilts during the luteal phase of the estrous cycle on plasma gonadotropins, follicular development, and ovulation rate. Journal of Animal Science 71 1546-1551.

Knox RV, Naber CH \& Zimmerman DR 1991 Follicle-stimulating hormone (FSH) during the secondary surge in gilts as influenced by administration of porcine follicular fluid (pFF). Journal of Animal Science 69 761-769.

Knox RV, Vatzias G, Naber CH \& Zimmerman DR 2003 Plasma gonadotropins and ovarian hormones during the estrous cycle in high compared to low ovulation rate gilts. Journal of Animal Science 81 249-260.

Ko JC, Kastelic JP, Del Campo MR \& Ginther OJ 1991 Effects of a dominant follicle on ovarian follicular dynamics during the oestrous cycle in heifers. Journal of Reproduction and Fertility 91 511-519.

Li MD, DePaolo LV \& Ford JJ 1997 Expression of follistatin and inhibin/activin subunit genes in porcine follicles. Biology of Reproduction 57 112-118.

Ling N, Ying SY, Ueno N, Esch F, Denoroy L \& Guillemin R 1985 Isolation and partial characterization of a Mr 32,000 protein with inhibin activity from porcine follicular fluid. PNAS 82 7217-7221.

Liu J, Koenigsfeld AT, Cantley TC, Boyd CK, Kobayashi Y \& Lucy MC 2000 Growth and the initiation of steroidogenesis in porcine follicles are associated with unique patterns of gene expression for individual components of the ovarian insulin-like growth factor system. Biology of Reproduction 63 942-952.

Lucy MC, Liu J, Boyd CK \& Bracken CJ 2001 Ovarian follicular growth in sows. Reproduction Supplement 58 31-45.

Medan MS, Watanabe G, Sasaki K, Sharawy S, Groome NP \& Taya K 2003 Ovarian dynamics and their associations with peripheral concentrations of gonadotropins, ovarian steroids, and inhibin during the estrous cycle in goats. Biology of Reproduction 69 57-63.

Miyamoto K, Hasegawa Y, Fukuda M, Nomura M, Igarashi M, Kangawa K \& Matsuo H 1985 Isolation of porcine follicular fluid inhibin of 32K Daltons. Biochemical and Biophysical Research Communications 129 396-403.

Miyamoto K, Hasegawa Y, Fukuda M \& Igarashi M 1986 Demonstration of high molecular weight forms of inhibin in bovine follicular fluid (bFF) by using monoclonal antibodies to bFF $32 \mathrm{~K}$ inhibin. Biochemical and Biophysical Research Communications 136 1103-1109.

Mukai S, Mori Y, Nagashima H, Hasegawa Y \& Hoshino K 1989 Changes in plasma gonadotropins, ovarian steroids and inhibin concentrations in gilts following progesterone treatment with implantable osmotic pumps. Animal Reproduction Science 20 287-297.

Noguchi M, Yoshioka K, Kaneko H, Iwamura S, Takahashi T, Suzuki C, Arai S, Wada Y \& Itoh S 2007 Measurement of porcine luteinizing hormone concentration in blood by time-resolved fluoroimmunoassay. Journal of Veterinary Medical Science 70 1291-1294.

Ohnuma K, Kaneko H, Noguchi J, Kikuchi K, Ozawa M \& Hasegawa Y 2007 Production of inhibin A and inhibin B in boars: changes in testicular and circulating levels of dimeric inhibins and characterization of inhibin forms during testis growth. Domestic Animal Endocrinology 33 410-421.

Rivier J, Spiess J, McClintock R, Vaughan J \& Vale W 1985 Purification and partial characterization of inhibin from porcine follicular fluid. Biochemical and Biophysical Research Communications 133 120-127.

Roberts VJ, Barth S, el-Roeiy A \& Yen SS 1993 Expression of inhibin/activin subunits and follistatin messenger ribonucleic acids and proteins in ovarian follicles and the corpus luteum during the human menstrual cycle. Journal of Clinical Endocrinology and Metabolism 77 1402-1410.

Robertson DM, Foulds LM, Leversha L, Morgan FJ, Hearn MT, Burger HG, Wettenhall RE \& de Kretser DM 1985 Isolation of inhibin from bovine follicular fluid. Biochemical and Biophysical Research Communications 16 220-226.

Robertson DM, Giacometti M, Foulds LM, Lahnstein J, Goss NH, Hearn MT \& de Kretser DM 1989 Isolation of inhibin alpha-subunit precursor proteins from bovine follicular fluid. Endocrinology 125 2141-2149. 
Ryan DP, Yaakub H, Harrington D \& Lynch PB 1994 Follicular development during early pregnancy and the estrous cycle of the sow. Theriogenology 42 623-632.

Schwall RH, Mason AJ, Wilcox JN, Bassett SG \& Zeleznik AJ 1990 Localization of inhibin/activin subunit mRNAs within the primate ovary. Molecular Endocrinology 4 75-79.

Shores EM \& Hunter MG 1999 Immunohistochemical localization of steroidogenic enzymes and comparison with hormone production during follicle development in the pig. Reproduction, Fertility, and Development 11 337-344.

Sugino K, Nakamura T, Takio K, Titani K, Miyamoto K, Hasegawa $\mathrm{Y}$, Igarashi M \& Sugino H 1989 Inhibin alpha-subunit monomer is present in bovine follicular fluid. Biochemical and Biophysical Research Communications 159 1323-1329.

Sugino K, Nakamura T, Takio K, Miyamoto K, Hasegawa Y, Igarashi M, Titani K \& Sugino H 1992 Purification and characterization of high molecular weight forms of inhibin from bovine follicular fluid. Endocrinology 130 789-796.

Todoroki J, Noguchi J, Kikuchi K, Ohnuma K, Ozawa M \& Kaneko H 2004 Plasma concentrations of inhibin A in cattle with follicular cysts: relationships with turnover of follicular waves and plasma levels of gonadotropins and steroid hormones. Domestic Animal Endocrinology $27333-344$
Trout WE, Killen JH, Christenson RK, Schanbacher BD \& Ford JJ 1992 Effects of weaning on concentrations of inhibin in follicular fluid and plasma sows. Journal of Reproduction and Fertility 94 107-114.

van de Wiel DF, Erkens J, Koops W, Vos E \& van Landeghem AA 1981 Periestrous and midluteal time courses of circulating LH, FSH, prolactin, estradiol-17 $\beta$ and progesterone in the domestic pig. Biology of Reproduction 24 223-233.

van de Wiel DF, Bar-Ami S, Tsafriri A \& de Jong FH 1983 Oocyte maturation inhibitor, inhibin and steroid concentrations in porcine follicular fluid at various stages of the oestrous cycle. Journal of Reproduction and Fertility 68 247-252.

Woodruff TK, Besecke LM, Groome N, Draper LB, Schwartz NB \& Weiss 1996 Inhibin A and inhibin B are inversely correlated to folliclestimulating hormone, yet are discordant during the follicular phase of the rat estrous cycle, and inhibin A is expressed in a sexually dimorphic manner. Endocrinology 137 5463-5467.

Received 22 January 2009

First decision 2 March 2009

Revised manuscript received 6 September 2009

Accepted 24 September 2009 